\title{
ㄷ RETABLO DE SAN AGUSTÍN DE VALENCIA, OBRA DE MIGUEL DEL PRADO (1521)
}

\author{
MERCEDES GÓMEZ-FERRER LOZANO** \\ Departament d'Història de l'Art. Universitat de València \\ Mercedes.Gomez-Ferrer@uv.es
}

\begin{abstract}
Resumen: Este estudio confirma la autoría del pintor Miguel del Prado (+1521) a partir de documentación inédita para unas tablas que pertenecieron a un retablo realizado para el convento de San Agustín de la ciudad de Valencia que se conservan en el Museo de Bellas Artes de Valencia y en el Lazaro Galdiano de Madrid. Se certifica así la personalidad de Miguel del Prado, puesta en entredicho y se confirma un corpus de pinturas, entre las que se incluye también el retablo de San Vicente para el convento dominico de Museros y otra serie de trabajos.
\end{abstract}

Palabras clave: Miguel del Prado / pintura renacentista / retablos / Valencia / convento de San Agustín.

THE ALTARPIECE OF SAN AGUSTIN OF VALENCIA, BY MIGUEL DEL PRADO (1521)

Abstract: By means of a new documentary evidence, this text confirms the authorship of the painter Miguel del Prado (+1521) for a series of paintings that once belonged to a retable of the Augustinian convent of the city of Valencia, nowadays in the Arts Museum of Valencia and the Lazaro Galdiano Museum in Madrid. We analyse the personality of this painter, which has been controversial and confirm a corpus of paintings, that include the Saint Vicent retable for the dominican convent of Museros, among others.

Key words: Miguel del Prado / renaissance paintings / retables / Valencia / Saint Augustin convent.

\section{Introducción}

En un artículo reciente ${ }^{1}$ se analizaba la figura del pintor de retablos, Miguel del Prado ( +1521), planteando una personalidad propia claramente diferenciada de la del pintor Miguel Esteve, con quien formó una compañía de pintores en la ciudad de Valencia a comienzos del siglo XVI. En él se apuntaba a la clara existencia de dos pintores distintos a pesar de que en algunos estudios se había llegado a dudar de su figura, asimilándolo por completo a Miguel Esteve y llevándole casi hasta la desaparición. ${ }^{2}$ El presente texto viene a incidir en la figura de Miguel del Prado, aportando un documento que certifica un pago de un retablo conservado, el que en su día perteneció al convento de San Agustín de la ciudad de Valencia y que actualmente se encuentra disperso, que nos parece clave para poder confirmar la adjudicación de una serie de tablas a su mano y poder olvidar definitivamente esa hipótesis que anulaba su figura.

Miguel del Prado cuenta con una historiografía definida a partir de los documentos publicados por Tramoyeres $^{3}$ sobre la pintura realizada por ambos artistas, Esteve y del Prado, en la capilla de la casa

\footnotetext{
* Fecha de recepción: 15 de enero de 2019 / Fecha de aceptación: 14 de abril de 2019.

** Este trabajo se enmarca en el proyecto I+D financiado por el Ministerio de Economía, Industria y Competitividad, HAR2017-83070-P, Geografías de la movilidad artística: Valencia en Época Moderna.

1 GÓMEZ-FERRER, Mercedes, 2017, pp. 125-140.

2 SAMPER, Vicente, 2015.

3 TRAMOYERES, Luis, 1919, pp. 73-100.
} 


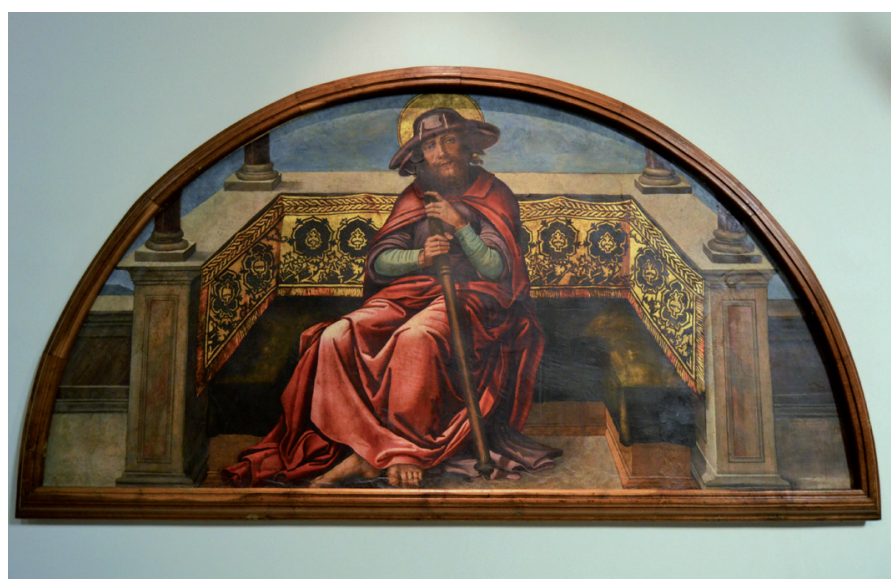

Fig. 1. San Jaime, Miguel Esteve y Miguel del Prado, 1519, Luneto de la antigua casa de la ciudad de Valencia, Museo Histórico Municipal de Valencia.

de la ciudad de Valencia (1519-20), obra parcialmente conservada y de complejo estudio, ya que precisamente al tratarse de una compañía resultaba difícil su adscripción a uno u otro autor (Fig. 1). Por tanto, para la consideración de las dos personalidades diferenciadas se habían utilizado otra serie de argumentos como era el de agrupar en torno a Miguel del Prado, las tablas que durante un tiempo se consideraron obra del Maestro del Grifo, ${ }^{4}$ un anónimo artista que recibió este nombre por los blasones con este animal fantástico que se encontraban en el retablo de San Vicente, procedente del convento dominico de Museros y conservado en la actualidad en el Museo de Bellas Artes de Valencia (Fig. 2). En razón de una serie de características formales, otras obras se aglutinaban en torno a estas, fundamentalmente unas tablas procedentes del antiguo convento de San Agustín de la ciudad de Valencia, sobre las que vamos a realizar una serie de precisiones, ya que el documento que constituye la base de este estudio se refiere a un retablo para el citado convento. Pero vayamos por partes en esta nueva aportación.

\section{La obra de Miguel del Prado}

Miguel del Prado como ha quedado demostrado 5 se encuentra documentado en Valencia con seguridad por un periodo muy breve de tiempo que no llega a 4 años. Entre diciembre de 1517, que contrataba el retablo de la capilla del Rosario para el convento de los dominicos, y el 18 de julio de 1521 fecha en la que muere en la batalla del camp de Morvedre en la guerra de Germanías. Un tiempo muy reducido en el que le vemos colaborar con Miguel Esteve en la pintura de muros y bóveda de la capilla de la casa de la ciudad y firmar un contrato para un retablo en el convento de Santo Domingo de la ciudad de Valencia que, como consecuencia de esta muerte prematura, no pudo acabar. Lo cierto es que este último contrato servía para afianzar una personalidad puesta en tela de juicio, porque su sola existencia le convertía en un pintor independiente, retablista y no meramente pintor decorativo, solvente como para poder contratar una obra de las dimensiones e importancia que tenía este retablo. Se trataba de un gran conjunto concertado con los Sorell, una de las más pudientes familias valencianas para una capilla recién construida y de gran devoción como fue la del Rosario en el convento de Predicadores. El resto de noticias sobre Miguel del Prado, hasta la publicación de este contrato, no pasaban de ser referencias genéricas a su vinculación con el movimiento agermanado y las relacionadas con los problemas surgidos por su muerte ab intestato, que ya quedaron resueltas en el citado estudio.

Esta nueva cronología que adelantaba en más de 16 años el fallecimiento de Miguel del Prado, de lo que hasta no hace mucho se suponía, tenía consecuencias inmediatas para el corpus que le había sido adjudicado. Por un lado, como se ha indicado, la crítica reconocía de una forma genérica que sus trabajos podrían localizarse entre los que se encontraban agrupados bajo el nombre que durante mucho tiempo se conoció como Maestro del Grifo. Este nombre de laboratorio fue pensado por Tormo para el pintor del retablo de San Vicente Ferrer, que conservado en el Museo de Bellas Artes de Valencia, procede del convento de San Onofre de Museros, en razón de los blasones que lo decoran donde figuran estos animales mitológicos. Por razones estilísticas, otras obras se unían a este corpus. Pero lo que se desprendía de la nueva datación es que todas tendrían que estar pintadas antes de julio de 1521 y en el caso del retablo de Museros podría resultar problemático en razón de la dependencia con respecto a obras de Sebastiano del Piombo, durante un tiempo creídas en Valencia no antes de esa fecha. El resto de obras no planteaba tantos problemas cronológicos y muchas de ellas podrían ser consideradas perfectamente como anteriores a 1521

${ }^{4}$ TORMO, Elías, 1932, pp. 19-24 y CATALÁ, Miguel Ángel, 1981, p. 42.

${ }^{5}$ Un resumen de las principales atribuciones y periplo vital de Miguel del Prado en GÓMEZ-FERRER, Mercedes, 2017. 
La obra de Miguel del Prado se corresponde con una serie de piezas de variada procedencia y temática que carecían todas ellas de documentación fehaciente, pero que guardaban estrecha componente formal, basada en la confrontación con los lunetos conservados procedentes de la casa de la ciudad y con el citado retablo de San Vicente Ferrer del Museo de Bellas Artes de Valencia, procedente de Museros. Este conjunto lo componían varias tablas. Entre otras, tres que representan la Adoración de los Magos con pocas variantes, de ahí su fácil adscripción, una en la colección Quílez, ${ }^{6}$ otra de la colección Montesinos ${ }^{7}$ y otra en la iglesia de Santo Tomás de Valencia, a la que acompaña la Disputa entre los Doctores en la misma iglesia. ${ }^{8}$ Tablas de la Dormición de la Virgen como la de la antigua colección Lassala, vendida en Sotheby's ${ }^{9}$ y una desaparecida en 1936 que estuvo en la iglesia de Villar del Arzobispo. ${ }^{10}$ Un San Pedro y un San Pablo del Museo de Valencia, estos últimos de atribución reciente ${ }^{11}$ y que plantean ciertas dudas, porque se encontraban en muy mal estado y, a pesar de su restauración, son obras que están muy dañadas. Además de algunas que han venido fluctuando y han sido adjudicadas tanto a Miguel Esteve como a Miguel del Prado, como un conjunto de cuatro pequeñas tablas con pares de santos de idénticas medidas: San Cosme y San Damián de los Serra de Alzaga, ${ }^{12}$ Santa María Magdalena y Santa Úrsula ${ }^{13}$ de colección particular, San Jorge y San Benito en colección extranjera ${ }^{14}$ y San Bernardo y San Sebastián, desaparecido. ${ }^{15}$ Últimamente todas ellas se han propuesto como obra de Miguel Esteve. ${ }^{16}$ Sobre las que había menos duda era otro grupo de tablas que podían estar relacionadas con un mismo retablo y que vendrían del convento de San Agustín de Valencia, ${ }^{17}$ entre las que

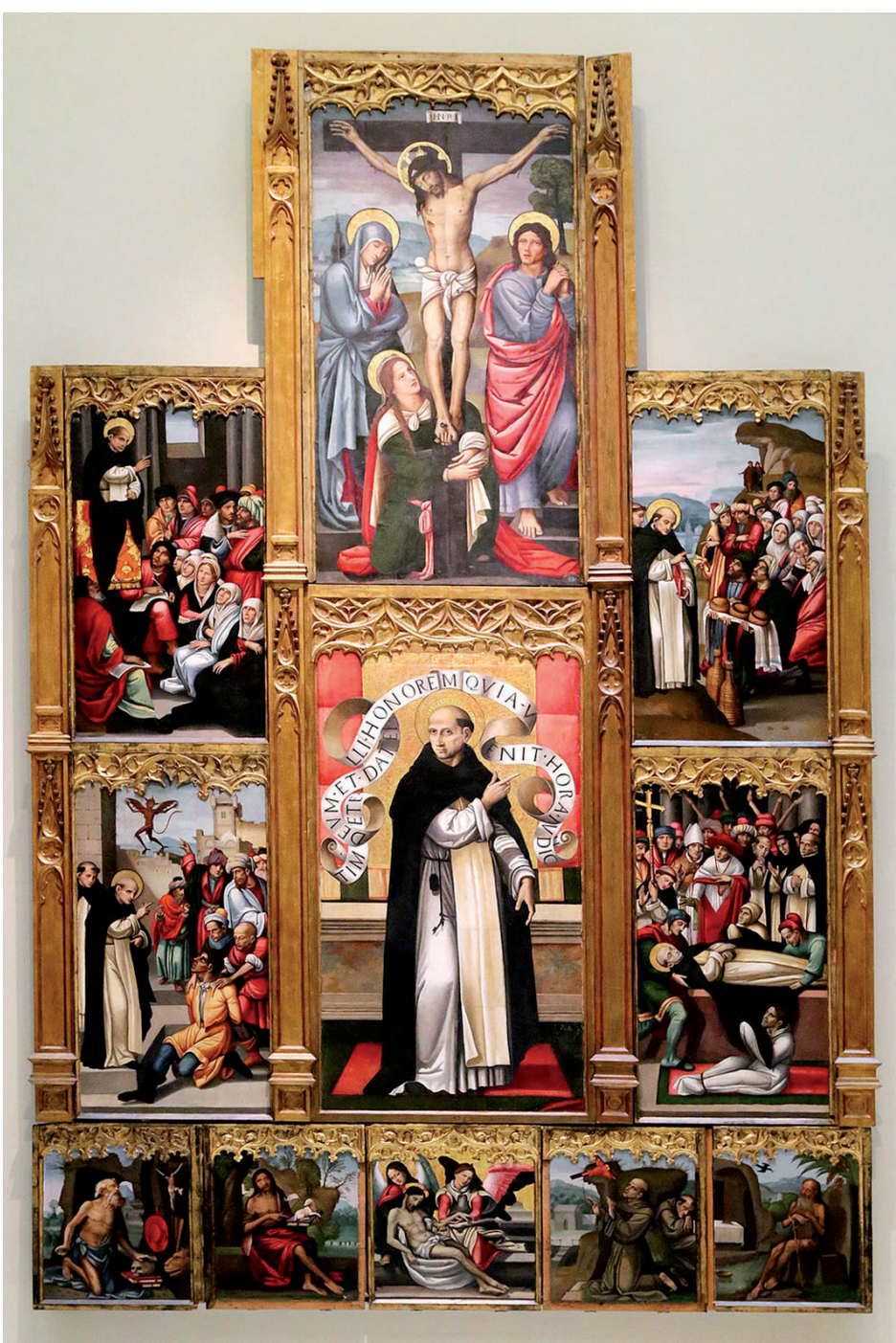

Fig 2. Retablo de San Vicente procedente del antiguo convento de Museros (Valencia), Miguel del Prado, Museo de Bellas Artes de Valencia, ca. 1517-1520.

\footnotetext{
6 COMPANY, Ximo; PUIG, Isidro, 2014, pp. 126-137.

7 POST, Chandler Rathfon, 1953, pp. 303-304.

8 POST, Chandler Rathfon, 1953, p. 301.

9 TRAMOYERES, Luis, 1919, p. 87 la publica como obra de los Hernandos. POST, Chandler Rathfon 1953, p. 329, consideró que era obra dudosa de Miguel Esteve, con posterioridad se ha dado como de Miguel del Prado y como tal aparece en Sotheby's en 2014.

10 POST, Chandler Rathfon, 1953, pp. 39-40 la consideraba de San Leocadio, pero COMPANY, Ximo, 2006, p. 349, indica que debe ser de Miguel Esteve o Miguel del Prado.

11 BENITO, Fernando, 2006a, pp. 224-225.

12 BENITO, Fernando, 2006a, pp. 220-223.

13 BENITO, Fernando, 2006a, pp. 222-223. Estuvo en la colección Lacuadra, se pensaba que podría proceder del mismo retablo que las piezas de San Agustín. Samper en 2006 propuso que procedían de un retablo de la iglesia de Torrent, compañeras del San Bernardo y San Sebastián en su día indicado por POST, Chandler Rathfon, 1953, p. 307.

14 GARCíA, Alfons, 2014 [hallazgo realizado por José Gómez Frechina].

15 POST, Chandler Rathfon, 1953, p. 307.

16 CEBRIÁN, Josep Lluis; HERNÁNDEZ, Lorenzo; NAVARRO, Beatriu, 2016, pp. 77-83.

17 SARALEGUI, Leandro, 1955, p. 332, señala el catálogo del Museo de 1847 con el $n^{\circ} 413$ como procedentes del convento de San Agustín, el San Nicolás y San Agustín con el nº 410 del catálogo impreso de 1850.
} 
se encuentran las de San Agustín y San Nicolás de Tolentino, ${ }^{18}$ y un Calvario ${ }^{19}$ en el mismo Museo de Bellas Artes de Valencia y un Santiago Apóstol de la colección Lázaro Galdiano. ${ }^{20}$

En ellas se advertía un pintor ya influenciado por el arte de Pablo de San Leocadio y de los Hernandos, con un cierta rigidez en sus figuras y composiciones. Una pincelada un tanto áspera y seca, que recorta con una delineación muy marcada las figuras contra los fondos. Los santos individualizados en posición frecuentemente frontal y algo planos y las composiciones con varias figuras que se agrupan creando perspectivas un tanto forzadas por rostros que se ocultan en varias filas superpuestas. Los escenarios son bastante someros y reducidos, sin excesivo detalle y con una cierta dureza geométrica. En algún caso, observamos también un frecuente abuso en la redundancia de modelos. Rostros que repiten las mismas características faciales, con narices prominentes y ojos muy saltones y marcados blancos por debajo del iris, o posturas totalmente reiterativas como las figuras del rey arrodillado y del rey Baltasar que señala con su mano hacia la Virgen y el niño, en las adoraciones de los Reyes Magos, que se repiten exactamente con el mismo gesto.

\section{Los retablos para el convento de dominicos de Museros}

Como hemos señalado este corpus se agrupaba en torno a la obra del retablo de San Vicente, una interesante pieza que se conserva en el Museo de Bellas Artes de Valencia y que procede del convento de dominicos de San Onofre de Museros, ${ }^{21}$ actualmente expuesta a falta de los guardapolvos. Este convento fue fundado en 1471 y prácticamente desapareció en la Guerra de la Independencia, por lo que lo que hoy se recuerda como Masía de San Onofre es fruto de transformaciones posteriores. Inicialmente fue un pequeño eremitorio, que se convirtió en convento y casa de novicios, con muy importantes moradores, entre ellos fray Luis Beltrán. También profesó en él y llegó a ser su prior fray Juan de Enguera, que fue el que encargó este retablo, como nos narra Diago en sus crónicas, señalando como "Acordóse mucho de su convento de San Onofrio, especialmente haciendo labrar en la Yglesia del una muy buena capilla y maravilloso retablo del bienaventurado San Vicente Ferrer, que hasta oy se llama de los Engueras". 22 Francisco Diago, cronista de la orden, conocía muy bien este convento, pues él mismo había hecho profesión en 1578 y fue su prior en dos ocasiones, 1602 y 1611. Fray Juan de Enguera fue uno de los más significativos dominicos de su época, alcanzando los títulos de confesor del rey Fernando el Católico y de Inquisidor General de la Corona de Aragón (1507-1513), así como vicario general de la Orden en la provincia de Aragón. Fue también obispo de Vic y Lleida y aunque fue nombrado de Tortosa, no llegó a tomar posesión por su fallecimiento el 15 de febrero de 1513. El retablo probablemente sucedería a una manda testamentaria que tendría prevista la dotación de su capilla en el convento, pero no es de extrañar que el retablo se contratara unos años después del fallecimiento como hemos visto que sucede en tantas ocasiones.

Como comentábamos al comienzo de nuestro texto, esta cronología anterior a 1521 para el retablo de San Vicente parecería incompatible con su realización, habida cuenta de que, como se ha señalado, ${ }^{23}$ algunas figuras, especialmente la del Cristo muerto en el centro de la predela, es dependiente del Cristo de la lamentación del Tríptico del Piombo, propiedad del embajador Vich. Esta obra se creía en la ciudad de Valencia no antes de 1521, cuando se presupone llegada al regreso del propio embajador procedente de Roma. ${ }^{24}$ Otras afinidades también indicadas con las obras del Piombo se han advertido para el San Jerónimo de la predela basado en el Adán del Descenso al Limbo del maestro veneciano. Esta posibilidad, como ha sido advertido, se podría resolver con las nuevas hipótesis esgrimidas recientemente que plantean la llegada de las obras de Piombo a Valencia poco

\footnotetext{
18 SARALEGUI, Leandro, 1944, p. 3. POST, Chandler Rathfon, 1953, pp. 287-288 las atribuía a Felipe Pablo de San Leocadio. CATALÁ, Miguel Ángel, 1994, pp. 204-207, las relaciona con Miguel del Prado.

19 CATALÁ, Miguel Ángel, 1994, p. 207. BENITO, Fernando, 2006a, pp. 226-227.

20 SAMPER, Vicente, 1998, pp. 274-276.

21 MOMBLANCH, Francisco, 1966, pp. 89-123.

22 DIAGO, Francisco, 1599, fol. 77v.

23 BENITO, Fernando, 2006b, p. 54.

${ }^{24}$ Obras propiedad del Embajador Vich que estuvieron en la ciudad de Valencia. Cristo de la Lamentación de Piombo, hoy en el Hermitage, Descenso al Limbo en el Museo Nacional del Prado.
} 
después de su ejecución en $1516 .{ }^{25}$ Así se podría explicar también la absoluta fidelidad que existe en otra obra que se fecha en la ciudad de Valencia hacia 1517 y cuyo autor es Fernando Llanos, ${ }^{26}$ La Flagelación de la colección Orts-Bosch, hoy en el Museo de Bellas Artes de Valencia, una de cuyas figuras reproduce casi de forma literal el soldado del Cristo Portacruz de Piombo.

El retablo de San Vicente es una pieza de gran interés pues responde a un momento en el que la figura de San Vicente Ferrer cobraba fuerza y adoptaba escenas de carácter más narrativo, una vez que su iconografía se había asentado a lo largo del siglo XV. Por un lado, podemos distinguir la consolidación del tipo de San Vicente Ferrer ${ }^{27}$ con el dedo apuntando al cielo, la filacteria, el libro cerrado y algunos otros atributos como las llaves y el tintero. Estos elementos ya se encontraban en la tabla atribuida a Joan Reixach que se expone en el Museo Meadows de Dallas, que pudo proceder del convento principal de la orden de la ciudad de Valencia y ser posterior a 1456 que es cuando se comienzan a recoger donativos para dotar la nueva capilla de San Vicente con un retablo. A partir de esa fecha se va consolidando la iconografía de San Vicente bastante reiterativa y muy abundante en la ciudad, a la que responde la tabla principal del retablo de Museros. Pero a ella se suman escenas narrativas de la vida del santo que comenzaron a ser más habituales a partir de 1510 cuando se publica la Vida de San Vicent Ferrer $^{28}$ escrita por Miquel Peres. Por un lado, milagros como la curación de un endemoniado y por otro, el milagro de los panes en el desierto. (Fig. 3 y Fig. 4) Estas dos escenas nos alertan de las carencias compositivas de Miguel del Prado pues de nuevo se resuelven de una forma bastante reiterativa. El San Vicente de perfil y en un lateral mantiene casi el mismo gesto en las dos tablas. Las figuras se aglomeran en el lateral contrario en disposición diagonal que oculta sus cuerpos dejando ver sus rostros agolpados. La escena de curación se sucede ante una interesante arquitectura fortificada en el fondo que bien podría corresponder a una vista de la Torre dels Angels del Real de Valencia, con sus dos contrafuertes redondeadas en las esquinas construidos hacia 1440 por
Baldomar ${ }^{29}$ la otra ante un somero paisaje. La escena de la Predicación, con el santo de nuevo en el mismo lateral, algo sobreelevado, que predica ante una multitud dispuesta de forma bastante similar a la de las anteriores tablas, representaría la conversión de lo que en su día serían musulmanes y que en el momento de la pintura de este cuadro responderían a moriscos. En todas las escenas se dan cita grupos de personas que podrían identificarse con cristianos viejos en convivencia con moriscos, caracterizados por sus turbantes. Esta misma forma de representación, aunque con distinta composición en torno al santo yacente, se repite en la escena del fallecimiento de San Vicente, al que rodean compañeros de hábito, un cardenal y un obispo, clérigos y otros moriscos con turbantes, con unas antorchas en el fondo. Algunos rostros son absolutamente repetitivos como el dominico de la derecha de esta última tabla que reproduce el del mismo San Vicente. Comisionado por fray Juan de Enguera que ostentaba importantes cargos relacionados con la ortodoxia religiosa, este retablo ha sido estudiado como un ejemplo de representación de la convivencia pacífica entre cristianos viejos y nuevos convertidos. ${ }^{30}$

Según palabras de Post, también hubo en este convento otro retablo "de la misma mano" dedicado a San Macario (de Egipto) encargado por la orden de Santiago, que aún se conservaba en 1934 en la iglesia parroquial de Museros, a donde se había trasladado, pero que desapareció en la guerra. ${ }^{31}$ Según Post, tenía como tema principal la figura de este santo vestido de benedictino y con un demonio encadenado. La orden de Santiago, vinculada a la población de Museros desde que aquella fuera entregada por el rey don Jaime I al finalizar la conquista, había auspiciado numerosas obras también el retablo mayor de la iglesia parroquial realizado por Joan Reixach, con temas de los gozos de la Virgen. Si este retablo de San Macario también puede ser atribuido a Miguel del Prado, como pensaba Post, que lo juzgó del mismo autor pero que lamentablemente no ilustró en su obra, podría sumarse a los varios encargos que del Prado recibió para lugares dominicos. Diago refiere que inicialmente estuvo en la capilla del Rosario del convento de Valencia pasando con

\footnotetext{
25 GÓMEZ FRECHINA, José, 2016.

26 GÓMEZ-FERRER, Mercedes; CORBALÁN DE CELIS, Juan, 2006, pp. 157-168.

27 CALVÉ, Oscar, 2016.

28 PERES, Miquel, Vida de Sant Vicent Ferrer, 1510

29 GÓMEZ-FERRER, Mercedes, 2012, pp. 88-89.

30 FRANCO, Borja, 2014-2016, pp. 21-52.

31 POST, Chandler Rathfon, 1953, pp. 296-301 y Tomo VI, p. 306.
} 


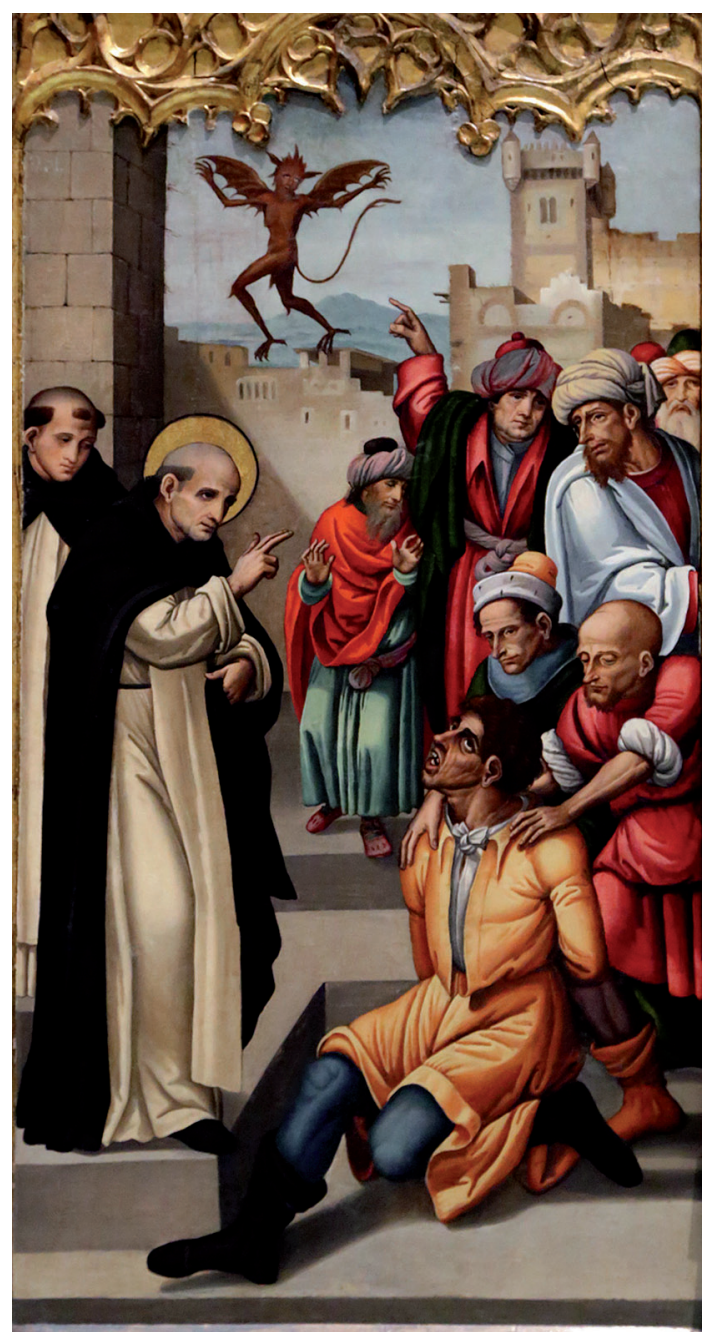

Fig. 3. Curación de un endemoniado, retablo de San Vicente del antiguo convento de Museros (Valencia), Miguel del Prado, Museo de Bellas Artes de Valencia, ca. 1517-20.

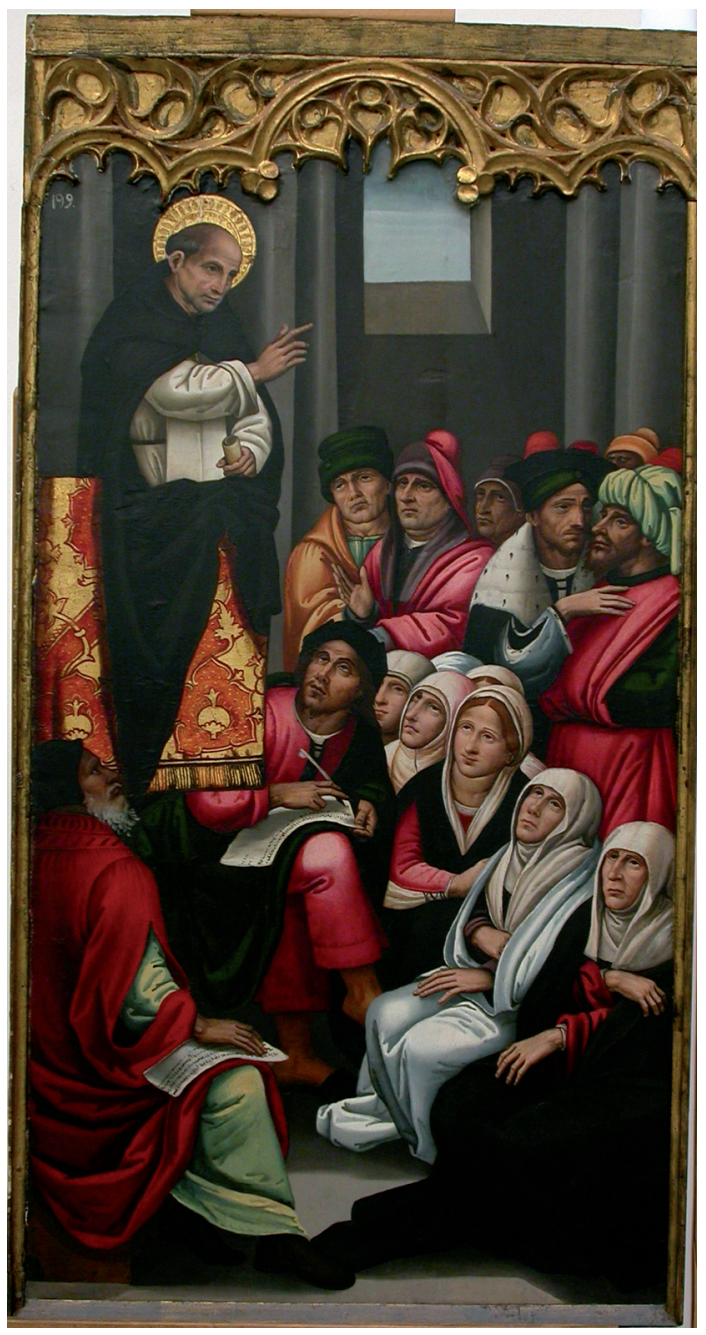

Fig. 4. Predicación de San Vicente, retablo de San Vicente del antiguo convento de Museros (Valencia), Miguel del Prado, Museo de Bellas Artes de Valencia, ca. 1517-20. posterioridad a la casa de novicios de Museros y que pudo ser encargo de Jerónimo Taix por entonces prior, quien luego escribiría una historia con los distintos milagros del Rosario. ${ }^{32}$

En realidad, pensamos que la advocación a San Macario propuesta por Post puede ser errónea y posiblemente se trataba de un retablo que narraba un suceso acaecido a uno de los priores del convento de Museros, fray Juan Amat, devoto del Santo Rosario. La tradición dominica ${ }^{33}$ recoge cómo este fraile libró a una joven endemoniada tras predicar en les Borges Blanques en Cataluña al tiempo que los demonios le perseguían mientras él se aferraba al santo Rosario. Diago informa que en la capilla de novicios del convento de San Onofre existía una pintura con este tema: "En medio de ella está el siervo de Dios con corona dorada de santo en la cabeça y con el rosario muy asido y los demonios delante que procuran quitárselo. Y más adelante la reyna del cielo con su hijo que acompañada de san-

32 DIAGO, Francisco, 1599, Libro 2, capítulo 98, fol. 284v.

${ }^{33}$ Hay varios libros que recogen los milagros relacionados con fray Juan Amat, el más importante es el de TAIX, Jerónimo, Llibre dels miracles de nuestra señora del Roser, 1556, capítulo XXI, p. 200 y el de OGEA, Fray Diego, 1589, Milagro $n^{\circ} 28$, pp. 67-68. 
ta Lucía y santa Marta le están diciendo Praedica Psalterium meum". ${ }^{34}$ La descripción de Post de un santo "benedictino y diablo encadenado" no puede ser otra que la de fray Amat como santo dominico y los demonios intentándole quitar el rosario. La devoción a San Macario el africano es inexistente en el medio valenciano y la confusión de Post puede estar fundamentada por el desconocimiento de este milagro, de carácter local, que tampoco cuenta con una gran difusión. La cronología de este retablo tampoco la podemos precisar con exactitud, ya que fray Juan Amat profesó en 1496, pero desconocemos la fecha precisa de su fallecimiento. ${ }^{35}$ No sabemos en qué momento pudo hacerse esta pintura y tampoco podemos asegurar que fuera obra de Miguel del Prado, porque carecemos de imágenes y no hay más descripciones que las citadas, pero las opiniones de Post acerca de las autorías se han venido considerando bastante acertadas, especialmente teniendo en cuenta que estaban los dos retablos en Museros cuando él los vio y juzgó que pertenecían a una misma mano. Quizá la pintura de un retablo secundario con un tema de devoción al Rosario le pudo servir de presentación a Miguel del Prado para poder considerarlo un pintor digno de recibir el importante encargo del retablo principal de la capilla del Rosario que al final no pudo cumplir.

\section{El retablo para el convento de San Agustín de Valencia}

Ante esta situación, ¿qué nos quedaba para poder certificar el estilo de Miguel del Prado y por ende su personalidad? Pues, prácticamente los restos de otro retablo que guardan estrecha conexión estilística con el de San Vicente Ferrer y se presentan también lo suficientemente alejados de la obra atribuida a Miguel Esteve como para considerarlos obra de un pintor distinto a aquel. Se trata del conjunto de tablas que, procedentes del convento de agustinos de Valencia, se han considerado todas pertenecientes a un mismo retablo. Las tablas de San Agustín (Fig. 5) y San Nicolás de Tolentino (Fig. 6), la Crucifixión del Museo de Bellas Artes de la ciudad de Valencia (Fig. 7) y la tabla de Santiago del Museo Lázaro Galdiano de Madrid (Fig. 8). Esta última fue atribuida por Samper ${ }^{36}$ al mismo pintor que las anteriores al considerar que podría tratarse de una tabla del mismo conjunto en razón de las dimensiones y por la propia composición de la misma.

Las tres tablas con los santos tienen todas unas dimensiones muy similares de $(105 \times 52 \mathrm{~cm}$.). A ellas se ha añadido el citado calvario $(143 \times 79 \mathrm{~cm})$ del Museo de Valencia que se considera pieza de la espiga, en una disposición parecida a la del retablo de San Vicente Ferrer. Las tres de Valencia se indican como procedentes de San Agustín en el inventario de Desamortización del Museo de $1838 .{ }^{37}$ Las tablas de los santos se han considerado posibles piezas de un guardapolvos, aunque son de unas dimensiones lo suficientemente grandes como para ser piezas laterales. El propio Samper con posterioridad ${ }^{38}$ y en razón de las similitudes de los nimbos de los santos proponía que otras dos tablas pudieran haber formado parte de este conjunto: un San Cristóbal de colección particular madrileña, publicado por Saralegui ${ }^{39}$ de medidas desconocidas y un San Miguel Arcángel del Museo de la ciudad, de dimensiones más reducidas $(84 \times 26 \mathrm{~cm}$ ). De ser así, difícilmente podemos considerar las tres tablas anteriores como piezas de un guardapolvos, ya que son de medidas compatibles con piezas laterales, en comparación con esta última.

El documento localizado ${ }^{40}$ certifica el total de los pagos por un retablo para el convento de San Agus-

\footnotetext{
${ }^{34}$ DIAGO, Francisco, 1599, Libro II, fol. 284v ${ }^{\circ}$.

35 VIDAL Y MICÓ, Francisco; TOMÁS MIQUEL, Serafín, 1735, Capítulo XIV; pp. 428-429, se indica que profesó en 1496, la fecha del fallecimiento sin embargo no es segura. DIAGO, Francisco, 1599, fol. $284 \mathrm{v}^{\circ}$ señala que figura aún en el capítulo de 1535 mientras que en el de 1538 celebrado en Zaragoza ya figura como fallecido. De ser un retablo de Miguel del Prado tenía que ser anterior a 1521 y por tanto muy cercano a los hechos milagrosos narrados.

36 SAMPER, Vicente 1998, pp. 274-276.

${ }^{37}$ Inventario de Desamortización de la Real Academia de Bellas Artes de San Carlos, 1838, números 10 (san Nicolás de Torrentino (sic), 56 (una tabla de San Agustín de pontifical) y 16 (una tabla con el crucificado, San Juan y la Virgen" procedentes de San Agustín. Esta procedencia se reitera en posteriores catálogos.

38 SAMPER, Vicente, 2015, pp. 148-149.

39 SARALEGUI, Leandro, 1955, Lámina II, pp. 331-333.

40 Archivo de Protocolos del Patriarca de Valencia, (APPV), notario: Joan Andreu, signatura: 19841, 29 de abril de 1521, "Ego Miquel del Prado pictor, gratis et scienter confiteor et in veritate recognosco vobis magnifice Ursole Coll et de Macip, relicte de Jacobi Macip quondam mercatoris dicte civitatis absenti etc in diversis vicibus et solucionibus dedistis et solvistis michi ego que a vobis habui et recepi mee omni modo de voluntati realiter numerando sexaginta libras monete regalium Valencie per vos michi debitas per pintura et dauratura cuisdam retabuli per me ad opus sepulture et capella vestre quod habens inter claustram Sancti Agustini dicte civitate coram capella pietatis presenti et daurati (...)".
} 


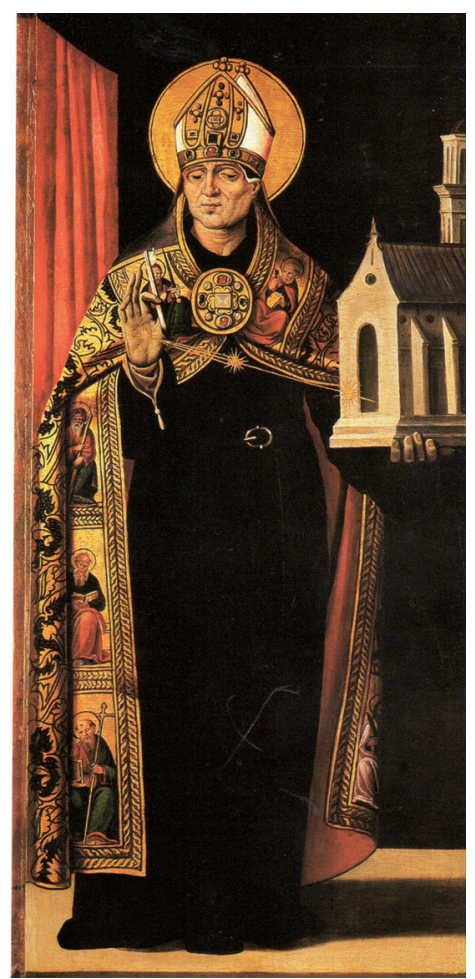

Fig. 5. San Agustín, Miguel del Prado, Museo de Bellas Artes de Valencia, 1521.

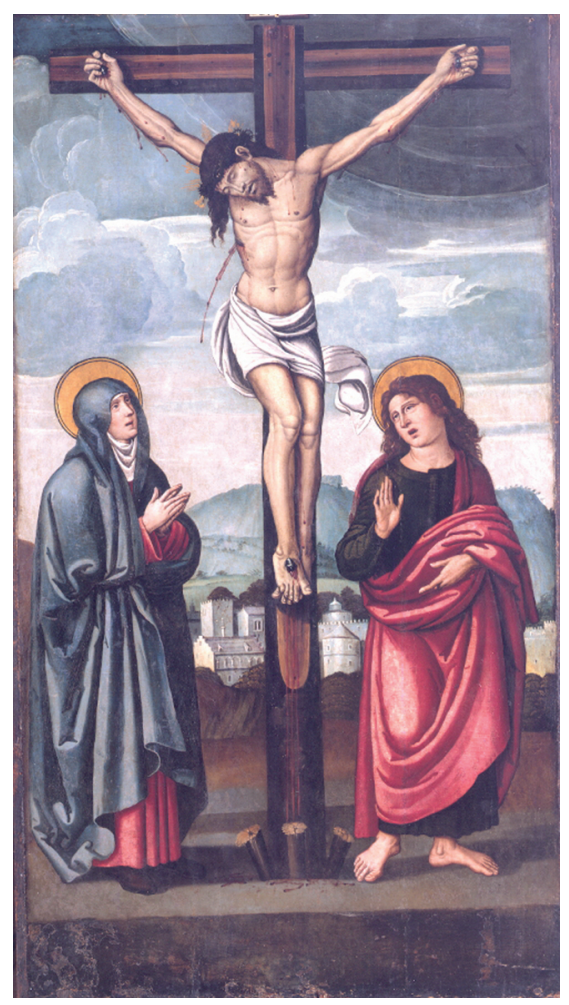

Fig. 7. Crucifixión, Miguel del Prado, Museo de Bellas Artes de Valencia, 1521.

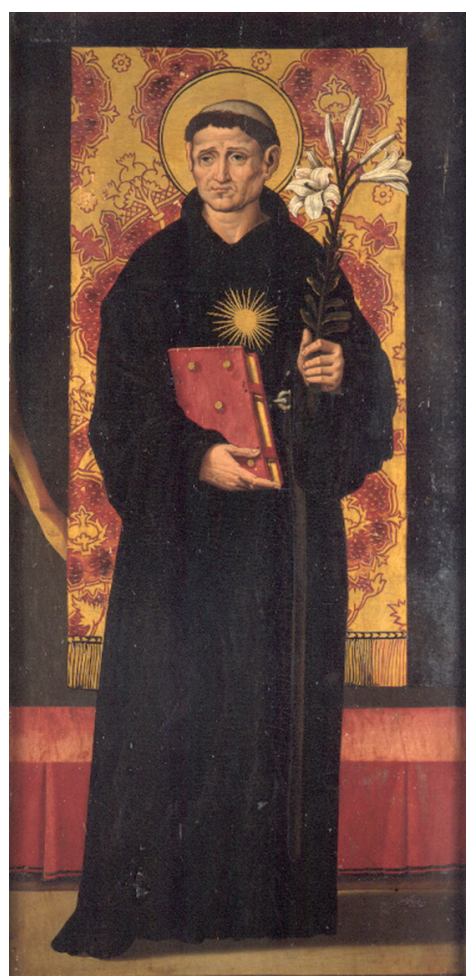

Fig. 6. San Nicolás de Tolentino, Miguel del Prado, Museo de Bellas Artes de Valencia, 1521.

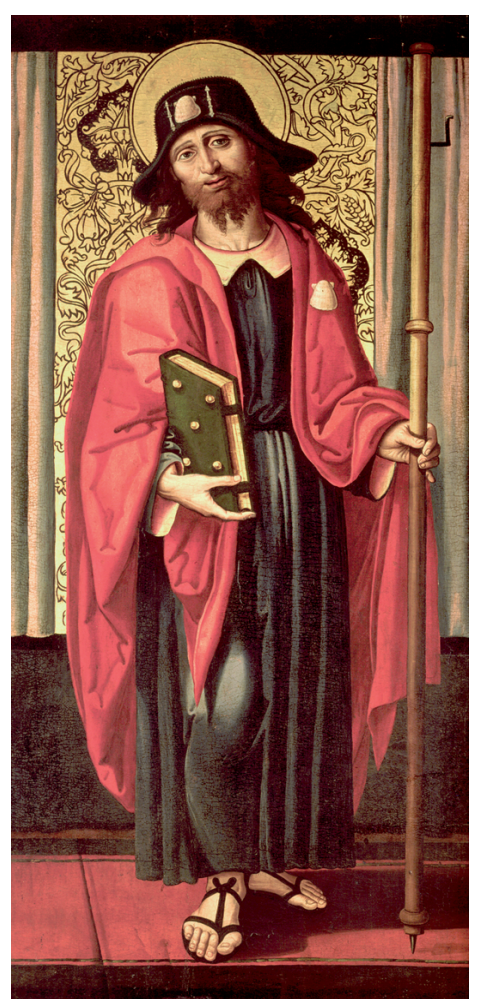

Fig. 8. Santiago, Miguel del Prado, 1521. @Museo Lázaro Galdiano. Madrid. 
tín a Miguel del Prado. En sí mismo, sería ya un dato significativo, porque de nuevo alude a un contrato de un retablo que sí que tuvo tiempo de finalizar el pintor, y por tanto, lo volvía a confirmar como maestro independiente de retablos. A pesar de ello, el documento tiene ciertas carencias al tratarse de un ápoca de pago y no de la capitulación con las características exactas del retablo. El 29 de abril de 1521, tan solo unos meses antes de su fallecimiento, Miguel del Prado certificaba que había cobrado un total de 60 libras, pagadas en diversas pagas, por parte de Ursola Coll y de Macip, viuda del mercader Jacobo Macip, por un retablo, cuya iconografía no se detalla, para la capilla sepulcral que tenían en el claustro del convento de San Agustín delante de la capilla de la Piedad.

El mercader Jacobo Macip había testado el 4 de agosto de 1519, falleciendo el 23 de septiembre de ese mismo año, pero estos documentos no se han conservado. ${ }^{41}$ Sin embargo, sí que hemos localizado el testamento de su esposa Ursola Coll fechado el 10 de septiembre de 1521, sin codicilo de lectura, pero que nos proporciona información sobre su familia y datos al respecto de la capilla. ${ }^{42}$ Ambos, casados desde el 15 de enero de 1486, vivían en Valencia en las inmediaciones de la parroquia de San Martín, en una casa y huerto cercana a las casas que el paborde Torrellas había arrendado a los Hernandos, pintores. ${ }^{43}$ Tenían un hijo de nombre Jerónimo Luis, ${ }^{44}$ que era el albacea testamentario, y varias hijas, Joana, Angela, Elionora, Anna, Ursola, Beatriz, Isabel y Yolanda. Debía ser una familia adinerada que había establecido relaciones con la nobleza de la ciudad, intentando ascender en el escalafón social. No obstante, la presencia de tantas hijas hacía que fueran necesarias importantes cantidades de dinero para poder dotarlas y casarlas con nobles destacados. Sabemos que la hija Eleonora, con una dote de 15.000 sueldos se había casado con el noble Felipe Lladró Cornell y para este matrimonio el marqués de Zenete había aportado 10.000 sueldos. ${ }^{45}$ Otra de las hijas Ángela se casó con Joan Lopez d'Anyó, doncel con una dote de 21.000 sueldos. $^{46}$ La propia Ursola Coll era heredera del ciudadano Luis Coll, que había fallecido sin testar, generando una serie de pleitos que se habían resuelto en 1517, permitiéndole cobrar su herencia. ${ }^{47}$ Sus negocios debían estar relacionados con el comercio de tejidos y paños, a juzgar por deudas que se reclaman ante notario, en las que se cita que se le debía dinero por tapices y por pieles de armiño. ${ }^{48}$

En su testamento Ursola Coll indicaba que deseaba ser enterrada en la capilla familiar dedicada a la Purificación donde yacía su marido en el claustro del monasterio de San Agustín, enfrente de la capilla de la Piedad. Esta advocación en principio podría parecer incompatible con los restos del retablo conservado, pero trataremos de razonar una posible explicación, que a falta de documentación más fehaciente no deja de ser hipotética.

Ya hemos indicado que algunos autores han considerado las tablas de San Agustín, San Nicolás Tolentino y San Jaime, posibles tablas de un guardapolvo, o en cualquier caso tablas laterales del retablo. La tabla principal por lo que se deduce del testamento debía ser una tabla de la Purificación con la crucifixión en la espiga. Intentar identificar este retablo con alguno de los que se conservaban en el monasterio antes de la Desamortización es tarea complicada ya que las descripciones no son muy explícitas. Contamos tan solo con un altar ci-

\footnotetext{
41 Por diversos documentos sabemos que Jacobo Macip había hecho testamento el 4 de agosto de 1519 ante Joan Fabra alias Benet notario, cuyos protocolos de esa fecha no se conservan. Había fallecido el 23 de septiembre de 1519.

${ }^{42}$ APPV, notario: Joan Andreu, signatura: 19841, 10 de septiembre de 1521, Testamento de Ursola Coll e de Macip, viuda de Jaume Macip, quondam mercader. Los albaceas testamentarios eran Bertomeu Carros doctor en leyes y Luis Macip, hijo de ambos. Quiere enterrarse en "(...) la sepultura en lo vas construhit dins la capella de la Purificació construhida en la claustra del monestir de Sent Agosti de la dita ciutat devant la capella o altar de la Pietat hon lo dit quondam magnific márit meu jau (...)", sin codicilo de lectura. El testamento se repite el 14 de marzo de 1523, APPV, Joan Andreu, 19844, los albaceas en este testamento fueron Fernado de Yxar, su yerno y Bernat Luis Macip su hijo. Su fallecimiento se produce el 6 de marzo de 1536.

43 APPV, notario: Jerónimo Arinyo, signatura: 14030, 31 de marzo de 1508.

${ }_{44}$ APPV, notario: Joan Andreu, signatura: 19843, 6 de febrero de 1522, cartas nupciales entre Luis Macip y Magdalena Goçalbo, doncella, hija de Teresa y Johan Goçalbo, quondam mercader.

${ }^{45}$ APPV, notario: Joan Andreu, signatura: 19841, 18 de enero de 1521.

${ }^{46}$ APPV, notario: Joan Andreu, signatura: 19846, 19 de febrero de 1527.

47 APPV, notario: Joan Andreu, signatura: 19842, 1 de marzo de 1520, se indica que hubo una sentencia de la corte a su favor el 21 de noviembre de 1517 para poder cobrar la herencia de su padre Luis Coll que había muerto ab intestato. Se menciona una cantidad de 36.000 sueldos de herencia.

${ }^{48}$ APPV, notario: Joan Andreu, signatura: 19842, 2 de mayo de 1520, reconocimiento de deuda de los herederos de Baltasar de Gallach a Ursola Coll y de Macip por valor de 58 libras.
} 
tado por Ponz al entrar en la capilla de la Virgen de Gracia, que ya en esta fecha estaba medio desmembrado, y que podría quizá identificarse con este retablo, aunque no lo podemos afirmar con seguridad. Así lo describe: "(...) hay sobre la mano derecha un altar antiguo, digno de mucha estimación por sus pinturas, que parecen algo anteriores a la edad de Joanes, la tabla del medio es una circuncisión, hay muchos asuntos de santos y otros pertenecientes a la vida de Cristo executado todo con suma prolixidad y hermosura de colores, a lo que se ha de añadir cierta simplicidad y expresión sobre que $\tan$ poco alto se hace ahora, siendo parte tan esencial en las buenas pinturas (...)". 49

Por un lado, Ponz lo sitúa en época anterior a Juanes y no puede ser confundido con tablas de Juanes que en aquel momento se encontraban en la sacristía de la iglesia y que también cita, una de las cuales es la Asunción que se conserva en el Museo de Bellas Artes de Valencia y otras se localizan en colecciones particulares pero procedentes de San Agustín, como la Adoración de los Magos y Pentecostés. ${ }^{50}$ Por otro lado, al estar ya descabalado en esta época, podría haber reunido varias piezas de altares dispersos y no ser un retablo completo. La tabla principal citada por Ponz es una Circuncisión, iconografía que pudo haber sido confundida en una descripción apresurada, si es que era la de la Purificación, extremo que no podemos confirmar. En realidad se trata de dos escenas diferentes, una es la Circuncisión del niño propiamente dicha, y otra la Presentación del niño en el templo coincidiendo con la Purificación de la Virgen a los 40 días del nacimiento en lo que se conoce como fiesta de la Candelaria. El hecho de ser una escena en el templo, con la Virgen que lleva el niño en sus brazos y la presencia del sacerdote, pudo haber llevado a esta denominación, si es que el retablo realmente es el que tratamos. Aunque como hemos visto necesariamente no tiene que ser el mismo, o pudo haber estado ya totalmente desmembrado.

En cualquier caso, la iconografía de los santos conservada, puede responder bien al retablo del que estamos hablando. Por un lado, San Agustín, propio del titular del convento en el que se ubicaba el retablo; por otro, San Nicolás de Tolentino, santo agustino por el que en Valencia se tenía una gran devoción y que contaba con otras capillas con retablos en el convento agustino y Santiago, probablemente en alusión al nombre del donante de la obra, el mercader Jaume Macip. En cualquier caso, sea o no, el retablo descrito por Ponz, planteamos que estas tablas proceden de un retablo para San Agustín que tenía una serie de santos, que están en relación con las advocaciones y temas más reiterados en el convento agustino de Valencia, y que pudieron acompañar a una escena central con el tema de la Purificación y corresponder a la manda testamentaria del mercader Jaume Macip, ejecutada por su esposa Ursola Coll.

Sabemos de la veneración que existía en el convento por San Nicolás de Tolentino del que al menos había otras dos capillas. Como patrono de los agonizantes, de las almas del purgatorio y contra pestes y calenturas, había sido canonizado en 1445, y desde ese momento debió aumentar su devoción, como testimonia su presencia en varios retablos del convento en los que figura como santo titular. Sabemos de la dedicación de una de las capillas de la iglesia, que no puede ser confundida con una en el claustro, por parte de los Gallach. Mencionada en el testamento de Joan de Gallach en 1498, carecemos de noticias sobre la fecha de su retablo, ya que en ella se habían enterrado los miembros de esta familia desde mediados del siglo XV. ${ }^{51}$ Otra también claramente anterior, con un retablo que pertenecía a la mano de Joan Reixach, albergaba la tumba de la familia de Bertomeu Ros y su viuda Isabel. ${ }^{52}$ Con posterioridad, en la primera mitad del siglo XVII se sustituyó el retablo de la capilla de San Nicolás de Tolentino que estaba en la iglesia, quizá la antigua de los Gallach, por otro costeado por el valenciano fray Jaime López (1616-1670) y su pintura fue realizada por un fraile agustino, fray Vicente Guirri. Otros cuadros de esta capilla fueron pintados por Félix Troya (1660-1731). En cualquier caso, pinturas todas ellas o muy tempranas o muy tardías y que no pueden confundirse con el retablo que estamos analizando. ${ }^{53}$

Los tres santos de las tablas conservadas se representan de pie de forma frontal recortados contra

\footnotetext{
49 PONZ, Antonio, 1774, Tomo IV, pp. 121-122.

50 BENITO, Fernando, 2000, pp. 186-189.

51 Archivo del Reino de Valencia, notario: Joan Comes, signatura: 601, 8 de enero de 1498, testamento de Joan de Gallach, desea ser enterrado en la capilla de San Nicolás de Tolentino de la iglesia del convento de San Agustín, conocida como capilla de los Gallachs.

52 CERVERÓ, Luis, 1966, p. 30.

53 BENITO, Daniel, 2013, pp. 186-187.
} 
unos fondos que destacan sus figuras. San Agustín con algunos de sus atributos, vestido de pontifical, con una pluma en una mano en alusión a sus numerosos escritos teológicos y la maqueta de una iglesia en la otra. Tres estrellas unen estos atributos, mano, pecho y maqueta unidas por un haz luminoso. San Nicolás de Tolentino aparece representado con los elementos que se asocian a su iconografía, tonsurado, con un rostro demacrado asociado a la austera disciplina de privaciones a la que se sometía, con un lirio, metáfora del creyente que confía en Dios, un códice cerrado que evoca la observancia a la verdad revelada y una estrella radiante relacionada con los hechos de su vida. ${ }^{54}$ Santiago se presenta igualmente de frente portando una vara para el camino y un libro en la otra, con las tradicionales conchas de peregrino que lo identifican. Les une una misma forma de resolver el suelo, con un pavimento en el que apenas se esbozan unas líneas de perspectiva con las sombras arrojadas hacia el mismo lado, y unos fondos de brocado similares en las dos últimas tablas, mientras que la de San Agustín plantea una oscuridad solo interrumpida por un cortinaje carmesí en el lateral. En todas ellas se advierte un cierto hieratismo del que ya hemos hablado que se observa en muchas de las obras de Miguel del Prado, pero se pueden reconocer unos rostros enérgicos y diferenciados que los individualizan.

Creemos que la cronología del retablo, año 1521, el autor, Miguel del Prado, y la procedencia del convento de San Agustín, confluyen en poder identificar este pago con el de los restos de un retablo que terminó de desmembrarse tras la Desamortización, como demuestra la dispersión de las tablas conservadas. No podemos, sin embargo, concluir nada acerca de la propuesta de que las tablas de San Cristóbal y San Miguel citadas por Samper pertenecieran a esta mismo retablo también. Pero con este nuevo documento parece quedar certificada la personalidad independiente de Miguel del Prado como pintor de retablos, activo en la ciudad de Valencia, hasta 1521 y creemos que definitivamente resuelta la identificación del anónimo Maestro del Grifo con su persona.

\section{Bibliografía}

BENITO, Fernando. Joan de Joanes, Una nueva visión del artista y su obra, Catálogo Exposición, Valencia: Generalitat Valenciana, 2000.

BENITO, Fernando. "Fichas sobre las obras 80-84 de Miguel de Prado". En: BENITO, Fernando; GÓMEZ FRECHINA, José, La memoria recobrada. Pintura valen- ciana recuperada de los siglos XIV-XVI. Catálogo de exposición. Valencia: Generalitat Valenciana, 2006a, pp. 220-227.

BENITO, Fernando. "Fichas sobre 'La Flagelación' de Hernando Llanos". En: BENITO, Fernando; GÓMEZ FRECHINA, José, La colección Orts-Bosch en el Museo de Bellas Artes de Valencia. Catálogo de exposición. Valencia: Generalitat Valenciana, 2006b, vol. I, pp. 54-55.

BENITO, Daniel. "La iglesia barroca del monasterio de San Agustín de Valencia", Ars Longa, n²2, 2013 pp. 167-193.

CALVÉ, Óscar. La configuración de la imagen de San Vicente Ferrer en el siglo XV, Tesis Doctoral, Universitat de València, 2016.

CATALÁ, Miguel Ángel. Colección Pictórica del Excmo. Ayuntamiento de Valencia, $1^{\text {a }}$ Parte. Valencia: Ayuntamiento de Valencia, 1981

CATALÁ, Miguel Ángel. "San Agustín" y "Sagrada Familia en el taller de San José" en El Mundo de los Osona, Catálogo de Exposición, Valencia: Generalitat Valenciana, 1994, pp. 204-211.

CEBRIÁN, Josep Lluis; HERNÁNDEZ, Lorenzo; NAVARRO, Beatriu. Miquel Esteve. Pintor leonardesco de Xàtiva, Xàtiva: Uleye, 2016.

CERVERÓ, Luis. "Pintores valentinos: su cronología y documentación", Archivo de Arte Valenciano, 1966, $\mathrm{n}^{\circ}$ 37, pp. 19-30.

COMPANY, Ximo. Paolo de San Leocadio i els inicis de la pintura del renaiximent a Espanya, Gandía: CEIC, Alfons el Vell, 2006

COMPANY, Ximo; PUIG, Isidro. "Una adoración de los Reyes Magos de Miguel del Prado, (siglo XVI)", Ars renovatio, 2014, pp. 126-137.

DIAGO, Francisco. Historia de la provincia de Aragón, Barcelona: Sebastián de Cormellas, 1599.

FRANCO, Borja. "Algunas reflexiones sobre la alteridad religiosa en el arte moderno de la Corona de Aragón a través del retablo turolense de San Jorge de Jerónimo Martínez, el valenciano de San Vicente Ferrer de Miguel del Prado", Sharq Al-Andalus, 21, 2014-2016, pp. 21-52.

GARCÍA, Alfons. "Identificada una tabla renacentista valenciana en una colección extranjera". Levante$E M V, 15$ de abril de 2014 (en línea). En: https://www. levante-emv.com/cultura/2014/04/16/identificada-tablarenacentista-valenciana/1101593.htmil (fecha de consulta: 14-1-2019).

GÓMEZ-FERRER, Mercedes. "Miguel del Prado, pintor de retablos en Valencia. Su fallecimiento en las Germanías (1521)", Archivo Español de Arte, 2017, XC 358, pp. 125-140, DOI: https://doi.org/10.3989/aearte. 2017.08.

GÓMEZ-FERRER, Mercedes. El Real de Valencia, historia arquitectónica de un palacio desaparecido, Valencia: Institución Alfons el Magnànim, 2012.

GÓMEZ-FERRER, Mercedes; CORBALÁN DE CELIS, Juan. "Un contrato de los Hernandos para la capilla de les Febres de la Seo de Xàtiva en 1511", Archivo de Español de Arte, 2006, pp. 157-168.

GÓMEZ FRECHINA, José, A new Christ carrying the cross by Sebastiano del Piombo. The Venetian Painter's legacy in Spain, Londres: Colnaghi, 2016.

${ }^{54}$ PACE, Valentino, 2005, pp. 401-402. 
MOMBLANCH, Francisco. "El obispo inquisidor Fray Juan Enguera y el retablo vicentino del maestro del Grifo", Anales del centro de Cultura Valenciano, 1966, $n^{\circ} 51$, pp. 89-123.

OGEA, Fray Diego. Breve instrucción de la devoción, cofradía e indulgencias y milagros del rosario, Madrid: Viuda de Querino Gerardo, 1589.

PACE, Valentino. San Nicola da Toletino nell'Arte, Milán: Biblioteca Egidiana, 2005.

PERES, Miquel. Vida de Sant Vicent Ferrer, Valencia: Imprenta Joffre, 1510.

PONZ, Antonio. Viage de España, Madrid: Joachim Ibarra, Tomo IV, 1774.

POST, Chandler Rathfon. The Valencian School in the Early Renaissance (A History of Spanish Painting, t. XI, Cambridge (Mass), 1953.

SAMPER, Vicente. "Un Santiago Apóstol del 'Maestro del Grifo' en el Museo Lázaro Galdiano", Goya, 1998, núms. 265-266, pp. 274-276.
SAMPER, Vicente. Miguel Esteve (Xàtiva, h. 1485-Valencia, 1527), y algunas consideraciones más sobre la pintura valenciana de su época, Tesis Doctoral, Universitat de València, 2015.

SARALEGUI, Leandro de. "Para el estudio de dos tablas italianas y varias españolas", en Boletín de la sociedad española de excursiones, 1944, Madrid, tomo 68, 1 trimestre, pp. 23-37.

SARALEGUI, Leandro de. "Miscelánea de tablas valencianas", en Archivo Español de Arte, 1955, pp. 323-338.

TAIX, Jerónimo. Llibre dels miracles de nuestra señora del Roser, Barcelona: Pere Mompesat, 1556.

TORMO, Elías. Los Museos. Guías - Catálogo: Valencia, Madrid, vol. 1, 1932.

TRAMOYERES, Luis. "La capilla de los Jurados de Valencia", Archivo de Arte Valenciano, 1919, pp. 73-100.

VIDAL Y MICÓ, Francisco; TOMÁS MIQUEL, Serafín. Historia de la portentosa vida y milagros del valenciano apóstol de Europa, Valencia: José Estevan Dolz, 1735. 